\title{
A Systematic Review, Narrative Synthesis and Conceptual Framework for Social Marketing and Behavioural Economics as Influencers of Health Behaviours in Children.
}

Emily Budzynski-Seymour ${ }^{1 *}$, Samuel Tuvey ${ }^{2}$, Juliet Paterson ${ }^{3}$, Michelle Jones ${ }^{3}$ and James Steele ${ }^{1}$

${ }^{1}$ Solent University, Southampton, UK

${ }^{2}$ Coventry University, Coventry, UK

${ }^{3}$ Marjon University, Plymouth, UK

* Correspondence: emily.budzynski-seymour@solent.ac.uk

Please cite as: Budzynski-Seymour, E., Turvey, S., Paterson, J., Jones, M., \& Steele, J. (2019, September 24). The Two Converging Paths of Social Marketing and Behavioural Economics: A Systematic Review and Narrative Synthesis of Their Effect on Physical Activity and Nutrition Behaviours in Children. https://doi.org/10.31234/osf.io/kh37d

DOI: $10.31234 /$ osf.io/kh37d

\begin{abstract}
Effective and scalable strategies to encourage positive health behaviours in children remain an important public health challenge. The combination of behavioural economics and social marketing has potential to offer an insightful approach therefore the aim of this research is to conduct a systematic review, narrative synthesis and propose a conceptual framework for their combined effect on children's physical activity and nutritional behaviours. Two pre-registered systematic reviews adhering to the preferred reporting items for systematic reviews and meta-analysis guidelines were combined and 51 studies were included. 35 studies reported behaviour change, 2 reported no behaviour change, and the remaining 14 had descriptive outcomes exploring the implementation of the interventions. Studies investigated nutritional outcomes $(n=37)$, physical activity outcomes $(n=9)$, or both nutritional and physical activity outcomes $(n=5)$. The findings demonstrate the links between behavioural economics and social marketing, particularly in influencing the physical activity and nutritional behaviours of children. A conceptual framework is presented and to present to practical alignment of both strategies to advance the use of them in promoting physical activity and nutritional behaviours to children. The review highlights how both strategies have been used previously in research, and how they frequently result in behaviour change.
\end{abstract}

Key words: Physical activity, nutrition, social marketing, behavioural economics 


\subsection{INTRODUCTION}

The World Health Organisation [1] and the European Commission [2] advocate the importance of promoting positive health behaviours in children [3]. The early development of healthy practices, including partaking in physical activity and following a nutritionally balanced diet may play a prophylactic role in health outcomes [4]. In addition, other modifiable lifestyle behaviours that impact on child body weight, including sufficient sleep and screen exposure time [5] are important to consider as obesity is one of the most significant and prevalent health risks for children worldwide [6].

Physical activity is considered an essential part of a child's overall health and wellbeing [7]. The WHO [8] recommend that children should engage in at least 60 minutes of moderate to vigorous intensity physical activity (MVPA) every day, however it is consistently reported that few children meet these recommendations [9-10]. Participating in physical activity at any age elicits health benefits; in children physical activity aids healthy growth and development, optimises cardiometabolic function, and aids in the prevention of multiple chronic diseases. Recent research has found a decline in MVPA from early childhood [11-13]. As behaviours established at this early stage of life are likely to track into adulthood [14] it is imperative that positive health behaviours are established early on if the goal is to influence longer term behaviours.

In addition to physical activity, a nutritionally balanced diet is a key contributing factor to overall health. Children are aware of the role of healthy nutrition at an early age [4]. Despite this, underconsumption of fruit and vegetables and over-consumption of nutritionally poor "junk food" is common among children [15-16]. Physical activity, and the adoption of a healthy diet are two health related variables that substantially effect a child's health, and as such there has been a lot of research around promoting these positive health behaviours. Much of this research has focused upon how to influence them.

One strategy to influence behaviour that has become popular is the use of behavioural economics. Its increase in popularity may be attributed to its conceptual appeal, and its potential to offer low-cost unobtrusive solutions to many of the serious problems facing our society including overeating [17]. Behavioural economics exploits the psychological underpinning of human behaviour in terms of predicting decision making, ultimately influencing the decision in a positive way whilst still ensuring freedom of choice. In terms of physical activity interventions, behavioural economists aim to understand the complex decision to engage in physical activity [18] which is often governed by unconscious cognitive impulses like habit, fear, and bias, and therefore is inherently irrational [19]. This means that we may be susceptible to manipulation whereby suitable interventions can influence the decision-making environment to nudge individuals to make better choices [19].

Behavioural economics has been, so far, the most influential behavioural science in policymaking [20]. Social marketing on the other hand is often thought of as a separate approach, yet it uses behavioural economic strategies to promote behaviour change [21] although this has not been sufficiently acknowledged [20]. Social marketing can be defined as the use of marketing principles and techniques to influence a target audience to voluntarily accept, reject, modify, or abandon a behaviour for the benefit of individuals, groups, or society as a whole [22]. Social marketing typically uses the '4 $\mathrm{P}^{\prime}$ approach: product, price, place, and promotion [23]. Firstly, the product does not have to be a physical offering [24] but can relate to a behaviour or practice. Price refers to what needs to be done to obtain the product. Place is about how the product reaches the consumer. Finally, promotion signifies the use of advertising, public relations, promotions, media advocacy, personal selling, and entertainment vehicles [24]. 
Dessart and van Bavel described behavioural economics and social marketing strategies as "two converging paths", if combined, both disciplines could inform policy making in a way that only one strategy alone could not. The integration of social marketing to the application of behavioural economics strategies should be considered due to its potential to influence behaviour [20]. Similarities between the two approaches include that they both inform a similar range of policy areas, both focus on individuals as the starting point for the interventions, and that the individuals are persuaded and not coerced to ensure freedom of choice [20]. One example of a strategy that uses both behavioural economics and social marketing is the work by Change4Life developed by the UK government. Change4Life is a social marketing campaign designed to steer individuals towards making healthier lifestyle choices [19]. One aspect of the program involves getting people to sign up so they can receive email nudges to help towards healthier behaviours, using a key strategy of behavioural economics. In terms of social marking, it has a clear brand and uses TV adverts to deliver its message. Recent work by Change4Life targeted specifically at children, called the 10 minutes shake ups, has adopted the use of popular Disney characters and uses them to promote 10 minutes of exercise, aimed to help towards meeting their daily recommendations [25].

Change4Life is an example of how social marketing and behavioural economics approaches can be, and are being, combined as suggested by Dessart and van Bavel to create a potentially effective health-based behaviour intervention. Despite the potential benefits to using either of these strategies to influence behaviour, and some evidence from successful interventions, no systematic reviews to our knowledge have been conducted yet into the ways that these strategies can be used to influence health related behaviours in children. This could provide key evidence from past research to help inform future health-based interventions development, evaluation, and implementation. As such the aim of this research is to conduct a systematic review and narrative synthesis of both behavioural economics and social marketing strategies in relation to influencing children's nutritional and physical activity behaviours.

\subsection{METHOD}

The method is split into two separate parts. The original review was conducted in January 2019 and focused primarily on social marketing. Another review was planned to look at behavioural economics separately, however once both searches had been completed the overlap between the studies found was apparent and it was then decided that the two separate reviews would be merged into one, encompassing both strategies. This is described further in the following section.

\section{Part 1}

The review was registered with PROSPERO (CRD42019118679) in January 2019 and adhered to the preferred reporting items for systematic reviews and meta-analysis (PRISMA) guidelines. Four databases were searched in January 2019: PubMed, Science Direct, SPORTDiscus and Web of Science. The focus of the search was to identify those studies that employed a social marketing strategy for the aim of effecting either nutritional or physical activity behaviours in children. Multiple key words were used (refer to the registered protocol) which were agreed a priori and chosen as they linked to the research question. Studies were included up to January 2019 with no other date limits applied. The inclusion criteria were that studies had to be in the English language and include children up to and including 12 years of age and research nutritional or physical activity behaviours. Studies were included when the age range of children started below 12 years even if the higher age group exceeded 12 years old. Studies were excluded if they did not contain original research, were review articles, books, or studies that were not peer reviewed. No other exclusions based on study design were employed and studies including any healthy or unhealthy lifestyle behaviours were considered. 
Figure 1 illustrates the systematic review process for the social marketing research. The research was screened using an online tool, Covidence. 7489 studies were imported and screened after duplicates removed, 7253 were excluded at the title and abstract screening phase. This left 236 to be full text screened. Two researchers (EBS and ST) screened the studies with any disagreements being resolved through discussion and, if needed, the opinion of a third researcher. At this stage, 193 studies were removed for a variety of reasons including being research on the wrong population, or not providing original research; this resulted in 43 studies included in the review.

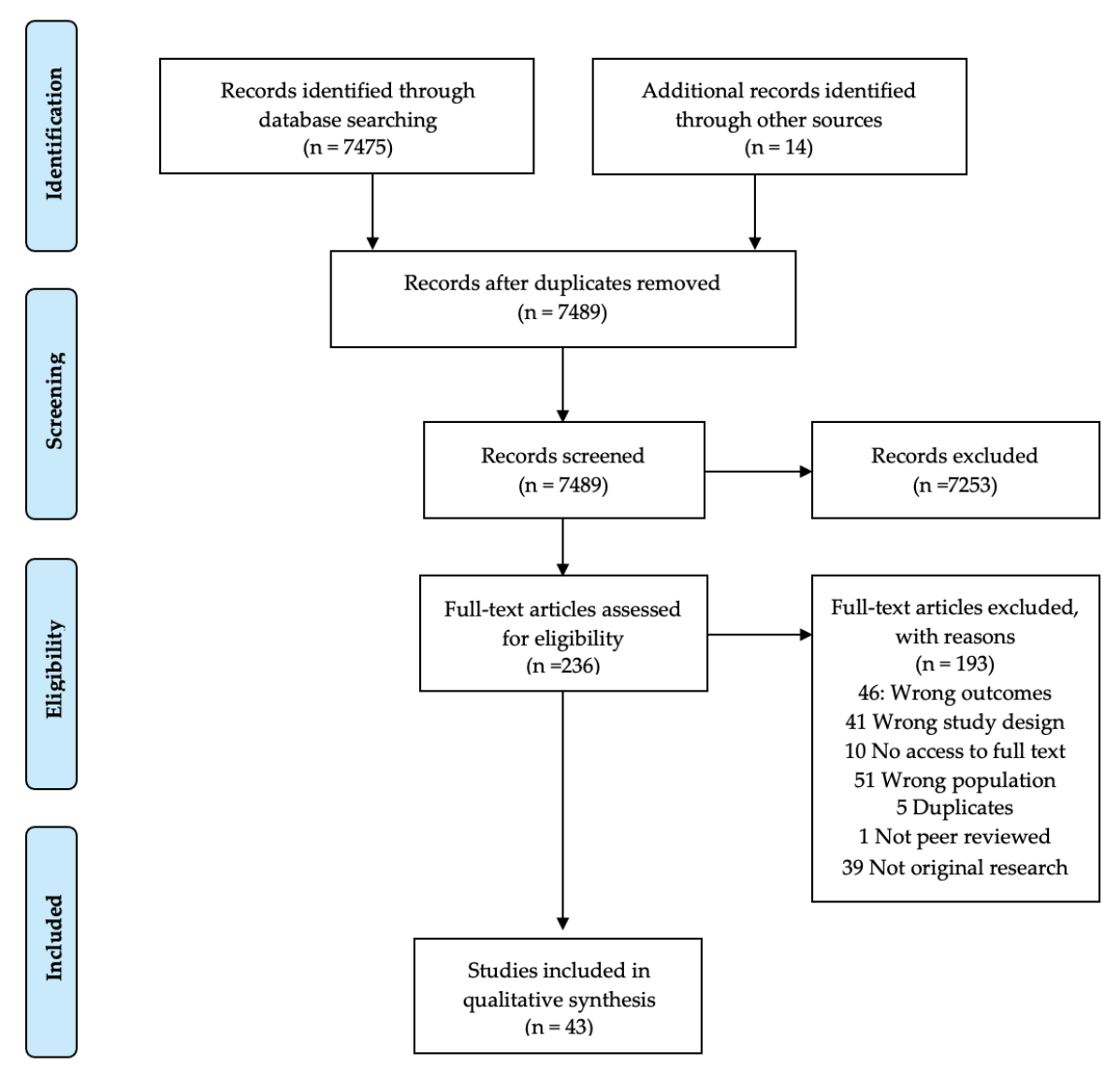

Figure 1: Social marketing PRISMA Diagram

Part 2

The second review was conducted in January 2020 and focused primarily on behavioural economics strategies and again the review adhered to the PRISMA guidelines. The same databases and inclusion/exclusion criteria were used to part 1 , however the focus of the search was to identify those studies that employed a behavioural economics strategy for the aim of effecting either nutritional or physical activity behaviours in children. Therefore, different multiple key words were used (refer to the registered protocol) which were agreed a priori and chosen as they linked to the research question. Studies were included up to January 2020 with no other date limits applied.

Figure 2 illustrates the systematic review process for the behavioural economics research. The research was analysed using an online tool, Abstrackr. 3628 studies were imported and screened after duplicates removed, 3568 were excluded at the title and abstract screening phase. This left 60 to be full text screened. Two researchers (EBS and ST) screened the studies with any disagreements being resolved through discussion and, if needed, the opinion of a third researcher. At this stage 52 were 
removed for a variety of reasons including being research on the wrong population, or not providing original research; this resulted in 8 studies included in the review.

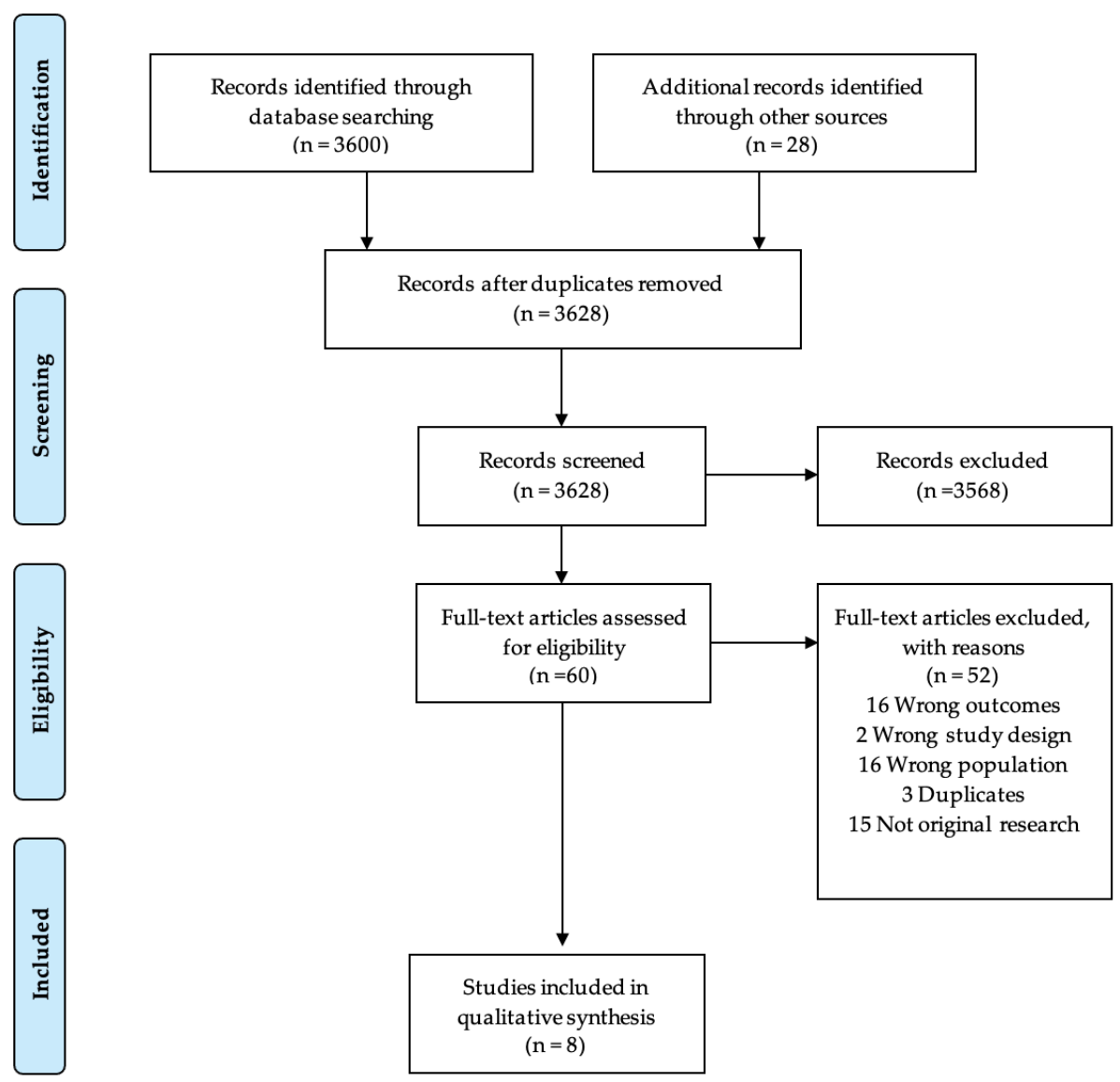

Figure 2: Behavioural Economics PRISMA Diagram

Part 3

After the two separate reviews were conducted it was decided due to their similarity and literature suggesting they are strategies that should be combined to further inform policy making, the reviews were merged into one larger review. In January 2020 the first review was updated to include the upto-date research from the preceding 12 months since the first literature search took place. The original pre-registration record on PROSPERO from January 2019 (CRD42019118679) was updated in January 2020 to reflect this and the final PRISMA diagram can be seen in figure 3. 


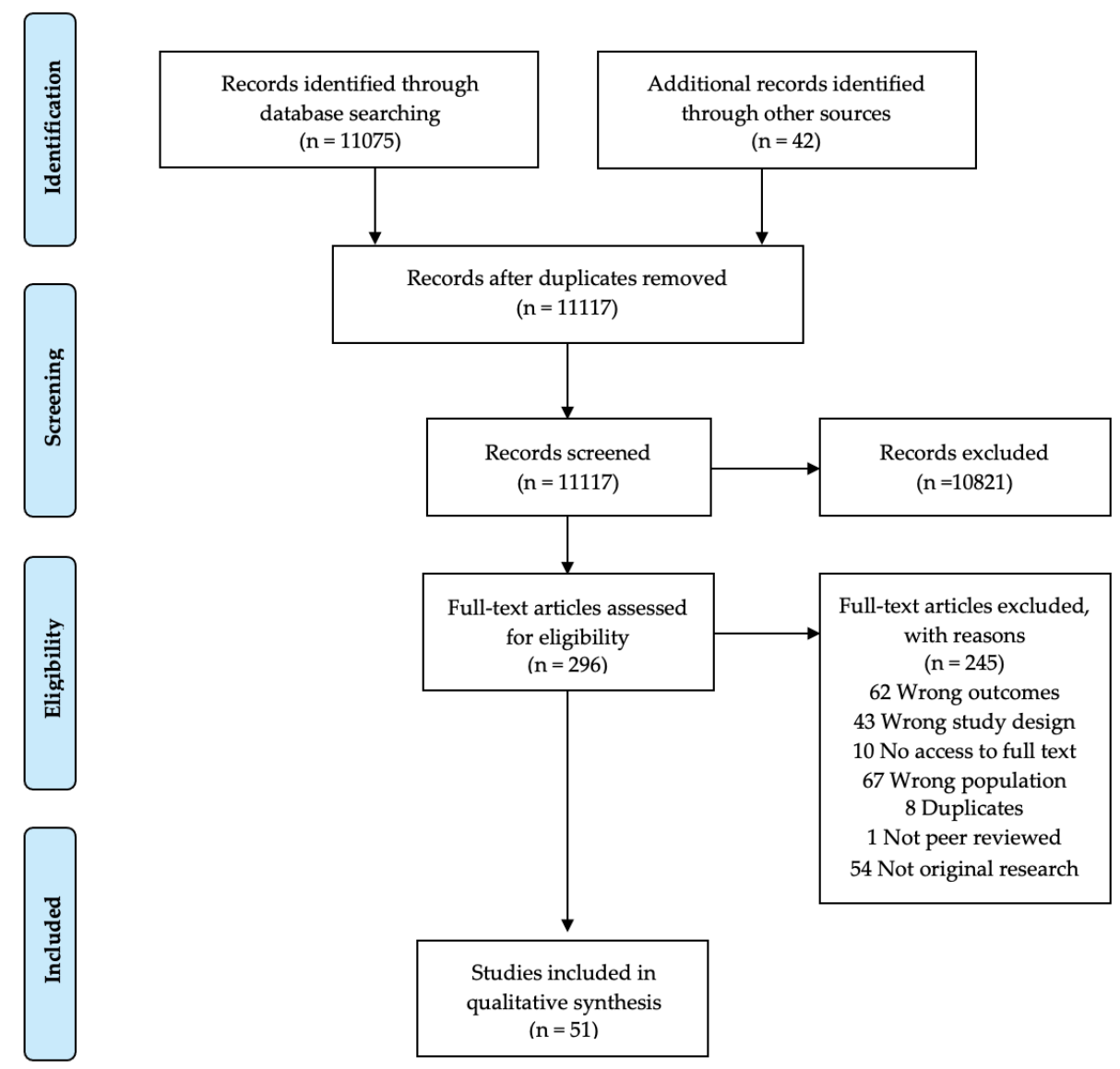

Figure 3: Combined PRISMA diagram

\section{Methodological quality}

The Mixed Methods Appraisal Tool (MMAT) was used to assess the methodological quality of the included studies [26]. The MMAT uses 19 quality criteria relating to the 5 methodological designs: qualitative, quantitative randomised controlled trials, quantitative nonrandomised controlled, quantitative observational descriptive, and mixed methods. This was done by two researchers (EBS and JP), any disagreements being resolved through discussion and, if needed, the opinion of a third researcher. High quality studies were considered to be those which score $80 \%$ or higher.

Identification of strategies incorporated

The identification of which social marketing or behavioural economics strategies were used for each study included in the review was conducted using the criteria in table 1. 
Table 1: Criteria for each strategy - Adapted from Kotler et al., and Matjasko et al., [22, 27]

\begin{tabular}{|c|c|c|}
\hline & Strategy & Criteria \\
\hline \multirow{3}{*}{ 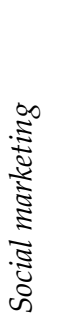 } & Product & $\begin{array}{l}\text { This relates to the behaviour being promoted, e.g., engagement in physical activity or the } \\
\text { promotion of healthy nutritional choices. }\end{array}$ \\
\hline & Price & $\begin{array}{l}\text { This is what needs to be "sacrificed" in order to gain the product, e.g., inactivity is the price to } \\
\text { sacrifice for activity, and un-healthy nutritional options are the price that needs to be } \\
\text { sacrificed for healthier options. }\end{array}$ \\
\hline & Place & $\begin{array}{l}\text { This is where and when the target audience will perform the desired behaviour, the location } \\
\text { of the promotion or the intervention being delivered e.g., a school-based intervention is at a } \\
\text { school }\end{array}$ \\
\hline \multirow{10}{*}{ 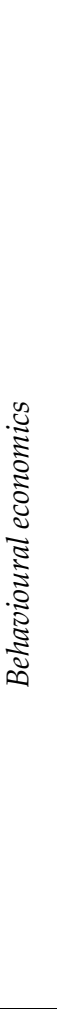 } & Promotion & $\begin{array}{l}\text { This is the methods that are used to promote the behaviour e.g., TV adverts, or brands or } \\
\text { incorporating characters }\end{array}$ \\
\hline & Messenger & $\begin{array}{l}\text { This relates to using someone or something to deliver the message e.g., a popular children's } \\
\text { character or a celebrity }\end{array}$ \\
\hline & Incentives & These are rewards or "things" used as motivation e.g., providing prizes \\
\hline & Norms & $\begin{array}{l}\text { This is anytime when the behaviour is being promoted as a normal and popular behaviour } \\
\text { e.g., organising a walk to school week where everyone is expected to walk to school }\end{array}$ \\
\hline & Defaults & $\begin{array}{l}\text { This relates to anytime the default is presented as the intended behaviour e.g., with a meal the } \\
\text { default side is a fruit bag, but this can be changed for an unhealthier option. }\end{array}$ \\
\hline & Salience & $\begin{array}{l}\text { This is when the target behaviour is promoted in a visible way or targeted as it is something } \\
\text { new e.g., telling children there is new PE equipment to play with in class and putting poster } \\
\text { up of it around the school. }\end{array}$ \\
\hline & Priming & $\begin{array}{l}\text { This relates to anytime when unconscious cues are used to influence behaviour, e.g., nudging } \\
\text { or framing. }\end{array}$ \\
\hline & Affect & $\begin{array}{l}\text { This is anytime when the behaviour is being promoted because of the way it will make the } \\
\text { children feel, or it is intended to make the children feel a certain way as emotions shape } \\
\text { decisions e.g., telling the children that this will be a fun and entertaining game to play. }\end{array}$ \\
\hline & Commitment & $\begin{array}{l}\text { This is anytime when pre commitment is needed, or pre commitment devices are used e.g., } \\
\text { asking people to sign up so they can receive email newsletters, getting them to set goals } \\
\text { beforehand or giving them a chart to track progress. }\end{array}$ \\
\hline & Ego & $\begin{array}{l}\text { This relates to anytime when the intended behaviour will make the children act in a way that } \\
\text { will make them feel better about themselves or telling them that this will make them feel } \\
\text { better e.g., telling the children being active and eating healthy will make you feel better. }\end{array}$ \\
\hline
\end{tabular}

\subsection{RESULTS}

51 studies were included in the review, a short description of each and key information extracted from each can be seen in table 2 . Studies investigated only nutritional based outcomes $(n=37)$, only physical activity based outcomes $(n=9)$, or both nutritional and physical activity outcomes $(n=5)$. Studies we conducted in North America $(n=28)$, Europe $(n=12)$, Australasia $(n=7)$, South America $(\mathrm{n}=3)$, and Asia $(\mathrm{n}=2)$. Thirty five studies had a sample size of $>250$ participants, 9 had a sample of between 250-999 participants, and 7 included a sample of $<1000$. There was research focused on both promoting a positive health behaviour $(\mathrm{n}=25)$ and research promoting a negative health behaviour $(\mathrm{n}=26)$. All papers were published in the 2000 's, with $22 \%$ of the included papers were published in 2019/2020. In total 35 papers (69\%) reported a behaviour change due to the intervention, with only 2 papers $(4 \%)$ reporting no behaviour change. Examples of behaviour change variables included consumption behaviours, BMI z-scores and physical activity levels. The remaining 14 papers $(27 \%)$ were focused more on exploring the implementation of the intervention and thus had more descriptive outcome outcomes (these are marked N/A in the table under the column behaviour change). 


\section{Nutrition}

There were 37 paper in this section, with a mean quality score of $75 \%$ and an average sample of 556 ranging from 27-11820. Two of the studies were qualitative $[57,33]$ mean quality score $100 \% .17$ were quantitative descriptive $[29,37,38,39,41,42,43,44,45,49,51,52,56,58,63,66,67]$ mean quality score $75 \% .5$ were quantitative non-randomised $[46,50,64,65,68]$ mean quality score $84 \% .12$ were quantitative randomised $[30,54,55,59,60,61,62,69,70,72,31]$ mean quality score $65 \%$ and one was a quantitative randomised cross over study [32] mean quality score $80 \%$. 11 of these papers were for a positive health related behaviour $[33,29,37,38,49,64,70,71,72,31,32]$ and the remaining 26 were for a negative health behaviour $[39,41,42,43,44,45,51,52,56,58,63,66,67,46,50,65,68,30,54,55$, $59,60,61,62,69,57]$.

\section{Physical activity}

There were 9 papers in this section, with a mean quality score of $78 \%$ and an average sample of 3331 ranging from 12-20818. Two studies were qualitative [35-36] mean quality score $100 \%$. Four were quantitative descriptive $[47,48,53,75]$ with a mean quality score of $70 \%$. One was quantitative nonrandomised [77] mean quality score $80 \%$. One was quantitative randomised [78] mean score $60 \%$, and one was mixed convergent [34] mean quality score $80 \%$. All of the papers were for a positive health behaviour [34, 35, 36, 47, 48, 53, 75, 77, 78].

\section{Nutrition and Physical Activity}

There were 5 papers in this section, with a mean quality score of $60 \%$ and an average sample of 1015 ranging from 133-4363. One study was qualitative [74] mean score $100 \%$. Three were quantitative non-randomised $[28,73,40]$ with a mean score of $40 \%$, and two were quantitative randomised $[73,76]$ mean score $60 \%$. All of the papers were for a positive health behaviour [73, 28, 40, 73, 76]. 


齐

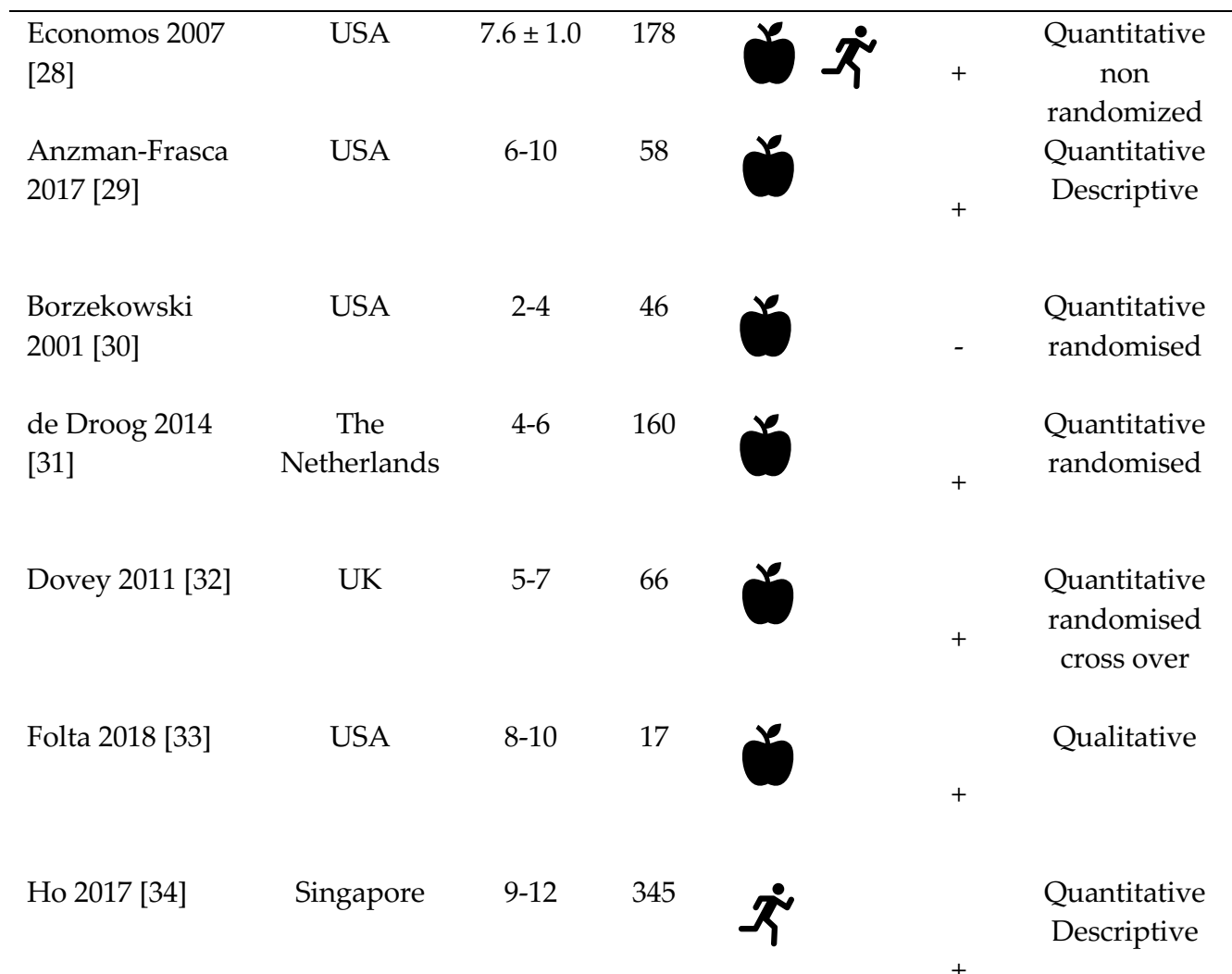

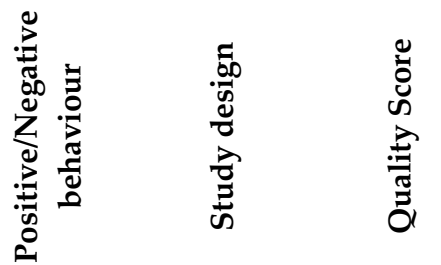

$80 \%$

Investigated an environmental change intervention's ability

to prevent weight gain in children, it reported reductions in BMI-Z scores in children at high risk for obesity.

Assessed perspectives on children's meals in restaurants, findings will be used to inform the development of

$60 \%$ restaurant interventions that are effective in promoting healthy eating.

Examined TV commercials influence over pre-schoolers $80 \%$ food preferences, found that even brief exposures can influence their preferences.

Investigated whether and how a picture book promoting carrots can increase children's carrot consumption. The

experimental group consumed nearly twice as many carrots as the control group.

Explored the role of food neophobia in response to food TV adverts in children. Children with low levels of food neophobia responded well to the healthy adverts but the children with higher levels did not.

Aimed to develop a branding strategy to improve the

$100 \%$ quality of food children brought in to school from home, the formative research provided information to create the

$$
\text { brand. }
$$

Explored presence in exergames as a mechanism that may be associated with positive mood experiences. Digital health interventions like exergames are a promising tool for increasing physical activity levels in children as physical activity is being framed as a game. 
Huhman 2005

[35]

Huhman 2008

[36]

Longacre 2015

[37]

Lopez 2018 [38]

USA

USA

Velazquez 2014

[39]

Williams 2014

[40]

Effertz 2019 [41]

Russia

10-18

Chambers 2019

[42]

New

Zealand

Emond 2019 (a)

Emond 2019 (b)

USA

[44]

Beaufort 2019

Austria
9-13

3120

$\dot{T}$

Descriptive

$+$

Quantitative

Descriptive

Quantitative

Descriptive

$4.7 \pm 0.6$
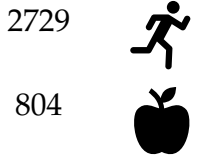

Quantitative

Descriptive

Quantitative

Descriptive

Quantitative

non

randomised

Quantitative

Descriptive

Quantitative

Descriptive

Quantitative

Descriptive

Quantitative

Descriptive

Quantitative

Descriptive
To determine the effects of a mass media campaign, high levels of awareness were reported showing that promoting physical activity with advertisements is a promising

$$
\text { method. }
$$

$60 \%$ Assess the immediate effects of a mass media campaign, prompted awareness of campaign was deemed high at 57\%.

Investigated using an entertainment based approach to

$60 \%$ promote fruit and vegetable to children. The children were

highly engaged in the programming with the fruit and

$$
\text { vegetables. }
$$

Pilot tested certain strategies to increase demand for the $80 \%$ healthier meals for children at a restaurant, more research was suggested to build on these findings.

Examined attention to food and beverage advertising and how this was associated with preferences, positive association found between length of time looking at

advertising and preference for that unhealthy food item.

Examined a childhood obesity initiative using a brand,

$0 \% \quad$ concluded that commercial marketing strategies may be an effective strategy for obesity prevention in youth.

Investigated the relationship between brand marketing and

$80 \%$ taste experienced, strong and positive brand effects were reported for brands effects on children's satisfaction.

Examine children's exposure to alcohol marketing via

$100 \%$ packaging, children are frequently exposed to alcohol

marketing meaning it is normalised in their environment

Investigated the influence of fast food advertising exposure on fast food intake, and the influence of parental fast food

intake. Advertisements for fast food may mitigate the

protective effects of infrequent parental fast food intake on children's fast food intake

Influence of food advertising and children's intake of the advertised cereal, brand specific high energy cereal

$80 \%$ advertisements were associated with consumption of these cereals.

Assessed how candy placements in films can influence

$100 \%$ children's selection behaviour in a shopping scenario, risk of
N/A

N/A 
Andreyeva 2011

[46]

Berkowitz 2008

[47]

Huhman 2007

[48]

Bezbaruah 2012

[49]

Boyland 2013

[50]

Bruce 2013 [51]

USA

The

Buijzen 2007

[52]

Colquitt 2014

[53]

Dixon 2007 [54]

USA

USA

USA

USA

UK

USA

($$
\text { 9-13 }
$$

20818

$\dot{4}$

8-11
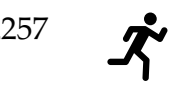

218

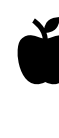

ตั

20

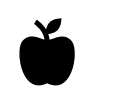

Netherlands

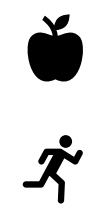

10-11
Quantitative

non

randomized

Quantitative

non

randomized

Quantitative

Descriptive

Quantitative

Descriptive

Quantitative

non

randomized

Quantitative

Descriptive

Quantitative

Descriptive

Qualitative

Quantitative randomised selecting a placed product was more than nine times higher in the experimental compared to the control group.

Investigated exposure to food advertising and children's $100 \%$ fast food and soft drink consumption, results suggests that these advertisements are associated with soft drink consumption in children.

Study assessed the awareness and understanding of a mass media campaign, and found that by providing communities with a higher dose of marketing activities and sustaining

those activities over time, there were more positive outcomes reported.

Assessed physical activity behaviours and attitudes at

$80 \%$ baseline and 2 years post a mass media campaign, a dose response effect was detected.

Investigate the influence of cartoon characters used in

$60 \%$ advertisement on children's fruit and vegetable preferences,

the most influential factors were taste.

Study looked to determine whether exposure to a celebrity endorser can influence intake, results found that they have an influence over intake in and out of a food commercial

$$
\text { context. }
$$

Evaluated the brain activation in response to logos in

thy and obese children, children were shown food logos and obese children had significantly less brain activation in

the areas of the brain associated with cognitive control.

Investigated food advertisement and consumption, it was

$80 \%$ found that the relationship between the two was present in lower income families.

A study investigated adapting an intervention to fit a rural

diverse community, results indicated that significant

changes were needed for the program for a different audience.

Compared food advertisement for junk food versus nutritious food, on children's food attitudes and preferences. There were positive findings for using advertisements to promote healthy foods. 


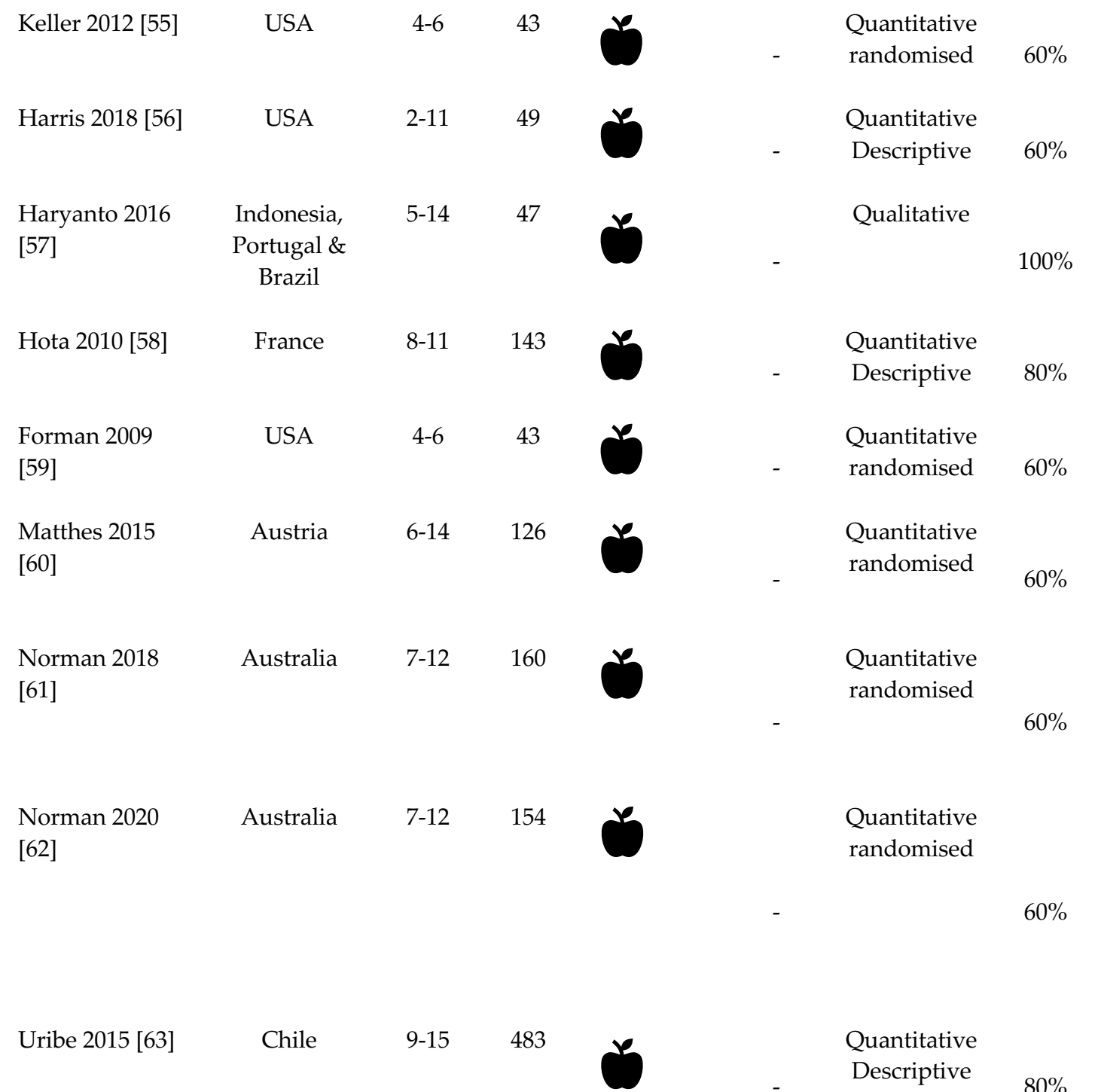

Investigated the effects of branding on children's eating, found that banding in an important influencer over what and how much children eat.

Measured the exposure and impact of food and beverage advertising to young children, the advertisement likely increases their preference for nutritionally poor food.

Research attempts to identify what antecedents are present for brand loyalty for children, and the findings help better understand children's buying behaviours in terms of the influence of brands.

Investigated public service announcements and their effects on children, child relevance was key as an antecedent for the effectiveness of pro nutrition messages.

Compared the influence of branding between healthy

weight and obese children, overweight children showed a greater responses to food branding.

Children's consumption behaviour in response to food

placement in films, results showed that exposure to the high

frequency product placement exerted a significant effect on snack consumption.

Study aimed to determine the relationship between parental feeding practices and children's intake responses to food advertising exposure. There was a susceptibility to food advertising among children whose parents report controlling feeding practices.

Investigated how exposure to different marketing

techniques from TV and online food advertising affects children's brand recall, recognition, and attitudinal responses toward brands and children's desire to eat the

advertised products. The marketing communications

increased children's brand recognition and elicited positive attitudinal responses.

Examined the effects of unhealthy food brand placement on children, both brand awareness and behavioural disposition towards junk food, these increased when children were exposed to marketing. 


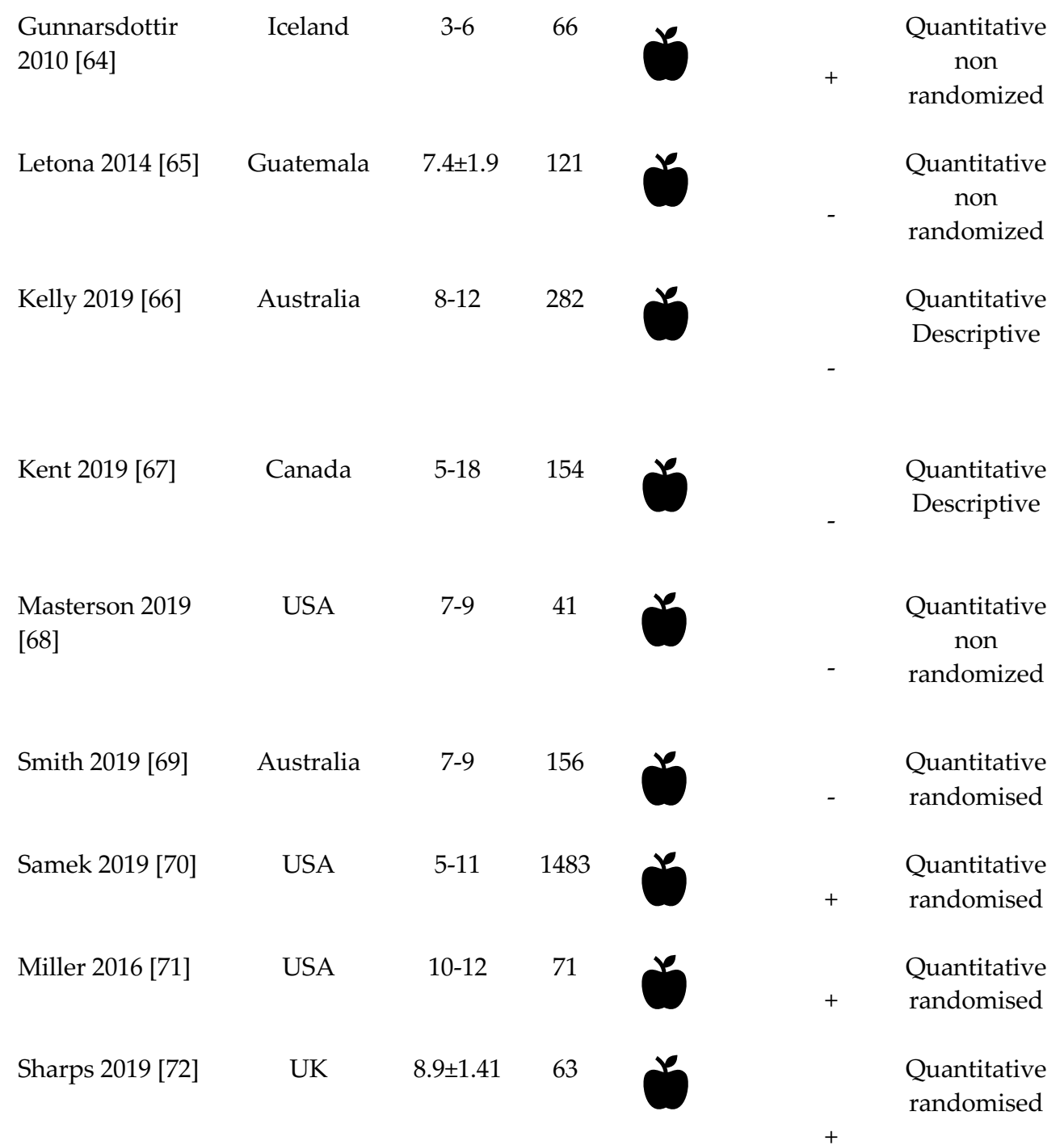

$80 \%$ eating, children have preference for child orientated wrapping and this could be a popular way to promote healthier eating among children.

Examined how licenced characters on food packages influenced children's taste and snack preferences, the inclusion of characters on food packaging influenced children's taste and snack preferences.

Explored children's emotional attachment to food and

beverage brands and their food marketing exposure.

$80 \%$ Concluded that reducing children's exposure to unhealthy

food and beverage advertisement is a must for

$$
\text { governments. }
$$

Investigated current food marketing exposure to children in schools and found that the current policies that should restrict marketing of unhealthy food to children is

$$
\text { inadequate. }
$$

Compared healthy weight and overweight children's brand responses to food commercials, no effects of consumption but for overweight children there were differences in brain activity when viewing the commercials.

Study explored and contributed to the understanding $60 \%$ around more modern techniques of food advertisements on children's food consumption.

Investigated using behavioural nudges to positively influence nutritional choices in children, small

$60 \%$ unconditional gifts increased healthy choices in children. Examined the effects of using nudges at school meal pre $60 \%$ ordering, nudging during pre-ordering lead to more orders of fruit and vegetables.

Investigated using pictorial nudges to promote healthier food for children. The results indicate that pictorial nudges on tableware influence children's fruit and vegetable

consumption. 


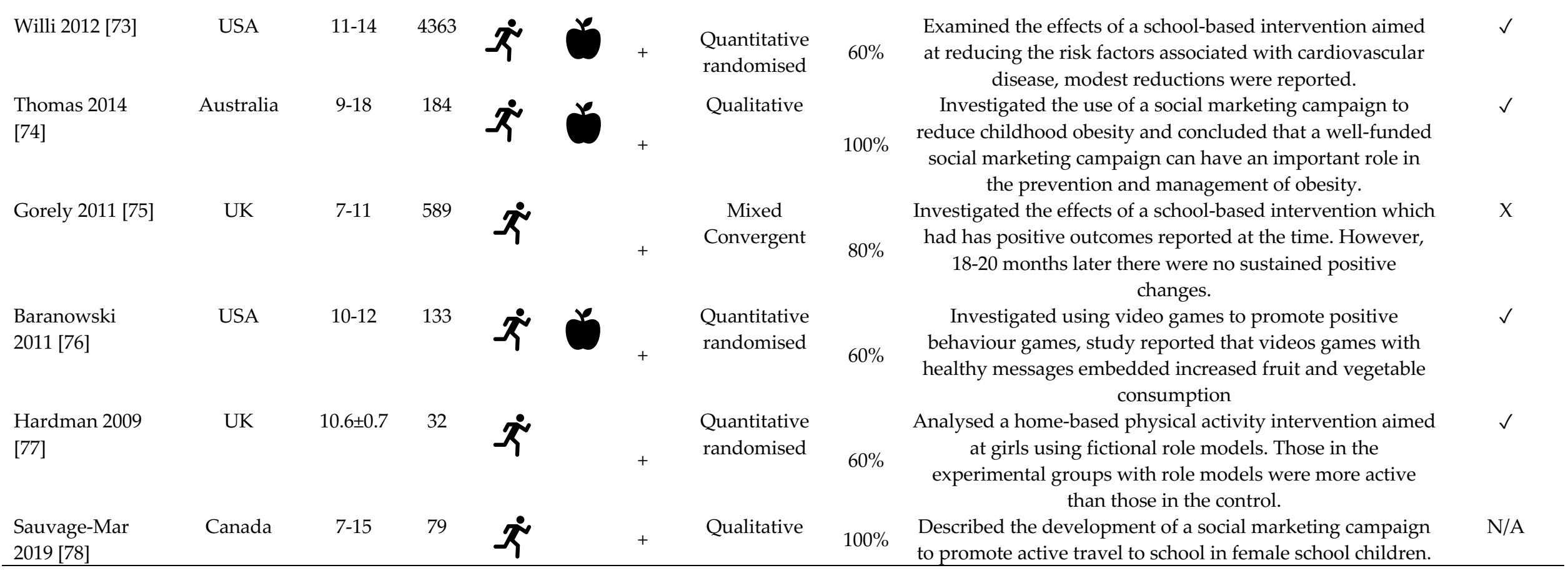




\section{Strategies incorporated and a conceptual framework}

All studies included in the review $(n=51)$ used both social marketing and behavioural economic strategies. Of the 13 strategies, the average number incorporated into a study was $6.1 \pm 1.7$ and ranged from 3-10. The combination of strategies varied considerably, however each strategies frequency was calculated. Product $(n=51)$, price $(n=47)$, place $(n=48)$, promotion $(n=50)$, messenger $(n=17)$, incentives $(n=13)$, norms $(n=5)$, defaults $(n=0)$, salience $(n=43)$, priming $(n=12)$, affect $(n=22)$, commitment $(n=2)$ and ego $(n=6)$. Table 3 illustrates which individual strategies were incorporated by each study.

Due to the fact that all studies included used both social marketing and behavioural economics strategies, a conceptual framework was developed as a holistic model to both illustrate and demonstrate how they can be, as they often are, used in unison to effect children's health related behaviours. Figure 4 illustrates this conceptual framework, incorporating both behavioural economics (dashed lined boxes) and social marketing (dotted lined boxes) strategies to influencing a child's physical activity or nutritional behaviour.

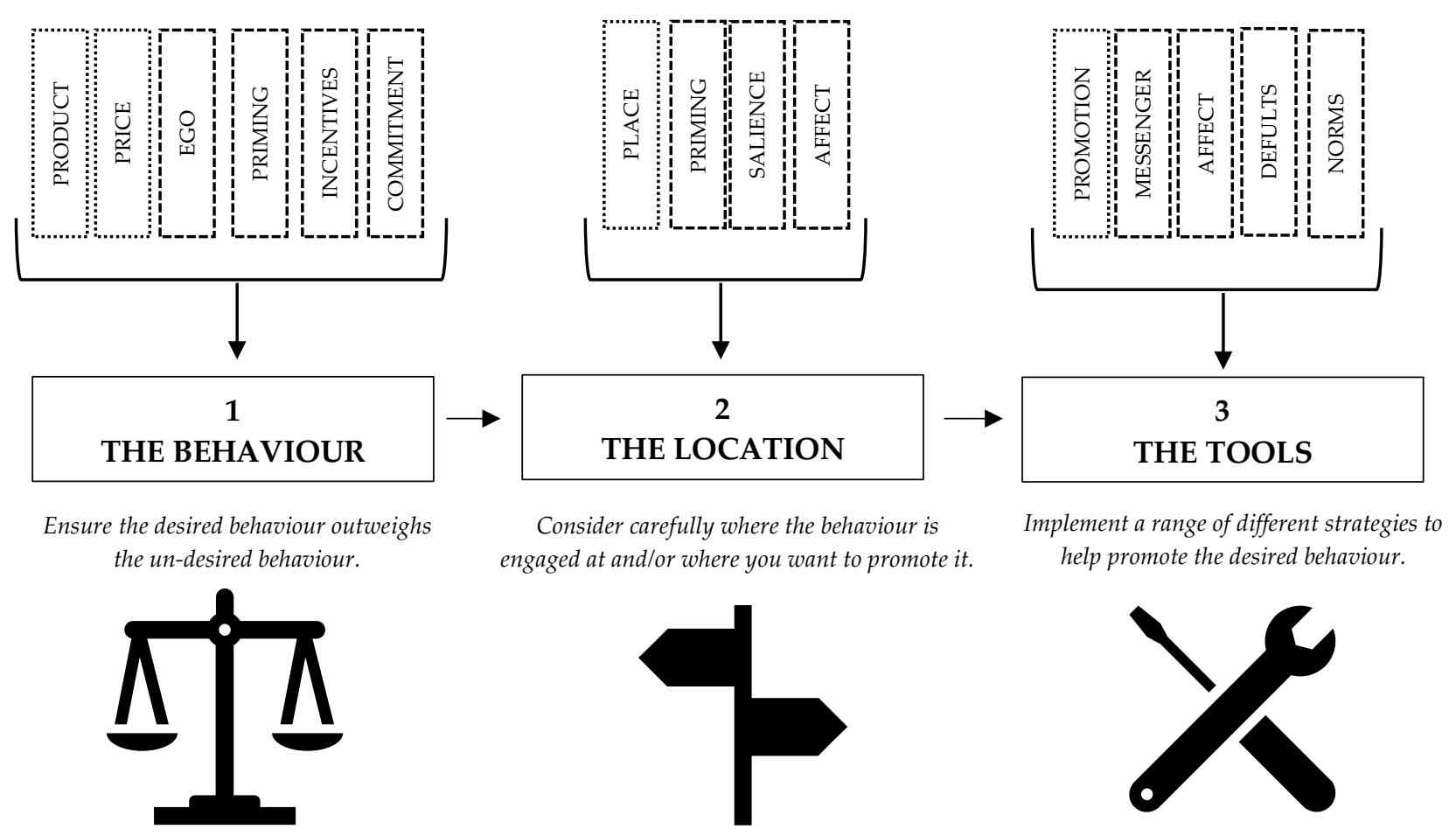

Figure 4: Conceptual framework for the holistic use of both social marketing and behavioural economics principles

Three sources were used in the development of this conceptual framework: experience, literature and theory [79]. Firstly, experience acted as a stimulus for the framework. As explained in the methods section these two concepts of behavioural economics and social marketing were initially seen as separate. However, reading the included papers provides some insight and experience into how these two concepts were consistently overlapping in the literature. This view was shared by Dessart and van Bavel [20] which meets the needs in the development of a framework for others in the field to share the view that addressing this will advance knowledge. Secondly the literature should provide evidence for the augmentation, this is shown in table 3 where the literature shows that all studies incorporated both social marketing and behaviour economics strategies. Finally, theory, the 
framework illustrates the individualist's theory from both of these strategies, but in a new holistic manner. This can be seen in the grouping of the strategies into the three stages shown in the conceptual framework, this can now be used as a structure to test this new proposed framework in future studies. Dessart van Bavel [20] described a number of similarities between the two strategies, including that they both had similar end goals of social good, they both used the citizen as a starting point, and that they adopt a multidisciplinary approach. This was then combined with the experience gained through reading the literature included in this review and developed into the three stages as illustrated in figure 4 . These were 1 ) the need to promote a certain behaviour (i.e., physical activity or nutrition) 2) the need to consider where to behaviour is engaged in and/or where to promote it, and 3 ) the need to employ the use of multiple tools as strategies to aid in influencing the behaviour.

Table 3: Strategies incorporated and links to conceptual framework

Social Marketing
Behavioural Economics

\section{Conceptual \\ Framework \\ Steps}

First author and year

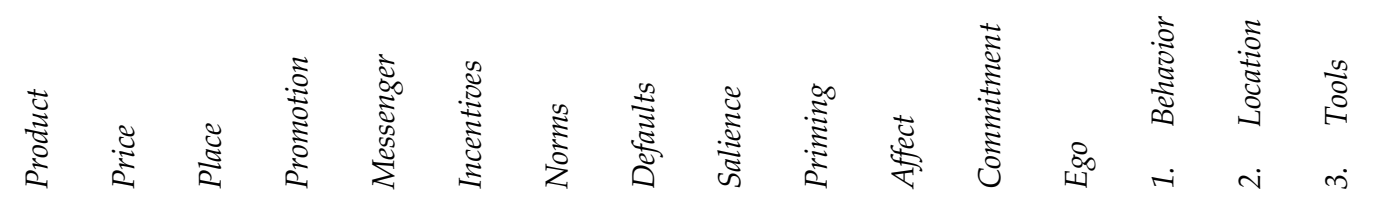

Economos 2007 [28]

Anzman-Frasca 2017 [29]

Borzekowski 2001 [30]

de Droog 2014 [31]

Dovey 2011 [32]

Folta 2018 [33]

Ho 2017 [34]

Huhman 2005 [35]

Huhman 2008 [36]

Longacre 2015 [37]

Lopez 2018 [38]

Velazquez 2014 [39]

Williams 2014 [40]

Effertz 2019 [41]

Chambers 2019 [42]

Emond 2019 (a) [43]

Emond 2019 (b) [44]

Beaufort 2019 [45]

Andreyeva 2011 [46]

Berkowitz 2008 [47]

Huhman 2007 [48]

Bezbaruah 2012 [49]

Boyland 2013 [50]

Bruce 2013 [51]

Buijzen 2007 [52]

Colquitt 2014 [53]

Dixon 2007 [54]

Keller 2012 [55]

Harris 2018 [56]

Haryanto 2016 [57]

Hota 2010 [58]

Forman 2009 [59]

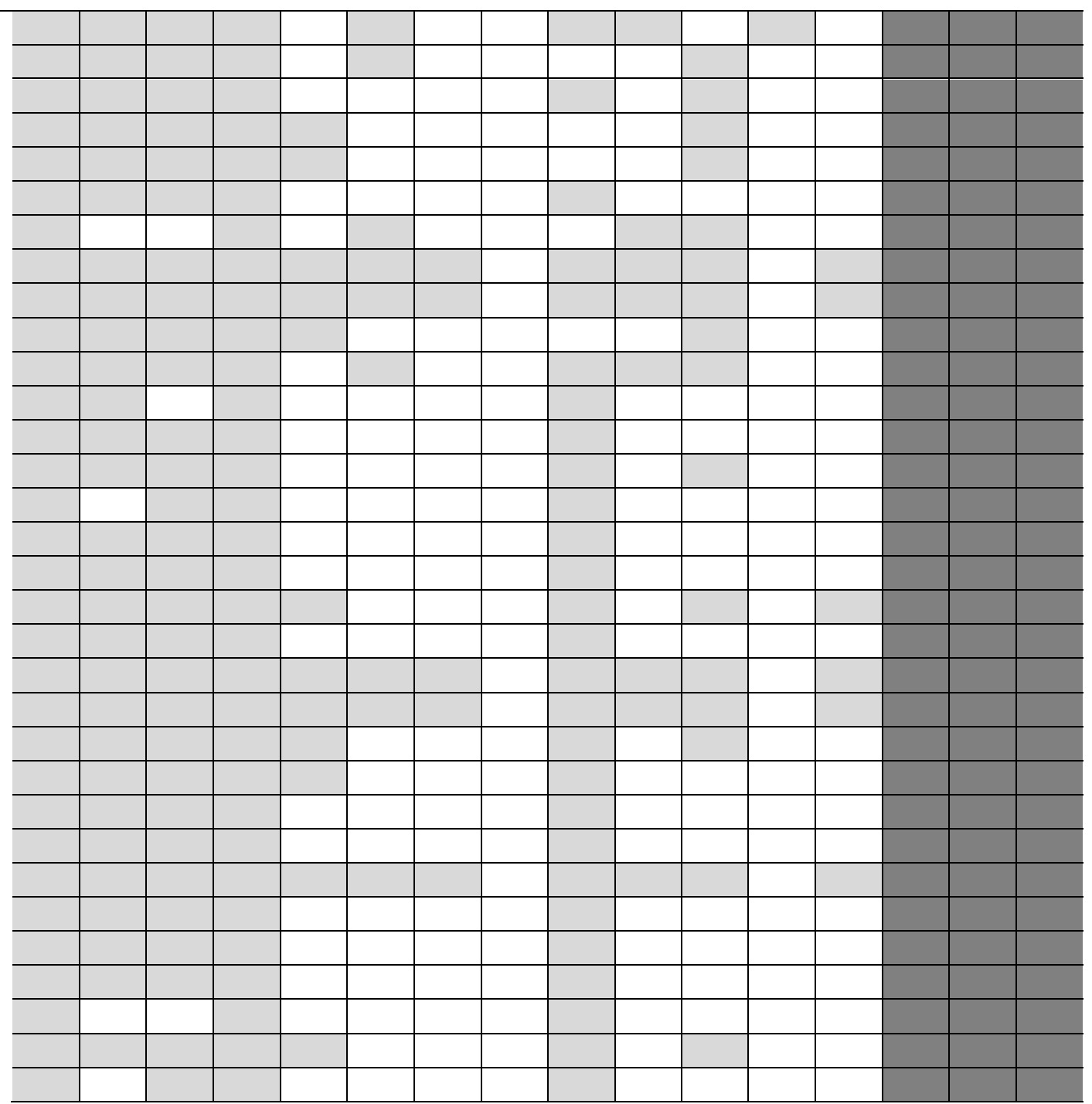


Matthes 2015 [60]

Norman 2018 [61]

Norman 2020 [62]

Uribe 2015 [63]

Gunnarsdottir 2010 [64]

Letona 2014 [65]

Kelly 2019 [66]

Kent 2019 [67]

Masterson 2019 [68]

Smith 2019 [69]

Samek 2019 [70]

Miller 2016 [71]

Sharps 2019 [72]

Willi 2012 [73]

Thomas 2014 [74]

Gorely 2011 [75]

Baranowski 2011 [76]

Hardman 2009 [77]

Sauvage-Mar 2019 [78]

\begin{tabular}{ll|l|l|l|l|l|l|l|l|l|l|l|l|l|l}
\hline & & & & & & & & & & & & & & & \\
\hline
\end{tabular}

\subsection{NARRATIVE SYNTHESIS}

The narrative synthesis below will provide evidence from the included studies to show how they have been using these strategies in a holistic manor to influence the health-related behaviours of children, and then provide links back as evidence for the new conceptual framework provided.

Step 1: The Behaviour - Ensure the desired behaviour outweighs the un-desired behaviour.

This first step refers to when strategies are employed to ensure that the desired behaviour outweighs the undesired behaviour. One way of doing this is through framing the behaviour in a certain way. In the review multiple studies incorporated framing to present the desired behaviour in an appealing way. Economos et al., [28] for example conducted a study where both physical activity and healthy nutrition were promoted. It was a school and home-based intervention where physical activity moves were framed as "cool moves". This intervention led to a reduction in the BMI z-scores of children who were at high risk of obesity. Framing was also used as part of the VERB ${ }^{\text {TM }}$ campaign. The VERB $^{\text {TM }}$ campaign was investigated in five studies in this review [35, 36, 48, 53, 47]. The campaign was launched in 2002 and used social marketing principles in an effort to increase the physical activity levels of children aged 9-13 years old [35]. The intention behind the campaign was to become the children's brand for physical activity, effecting behavioural norms by positioning physical activity as a highly appealing and easy choice, promoting it as fun and cool. Similarly to the previous studies, here physical activity itself was framed as "fun and cool". By framing it in this way it is suggested that the researchers hoped it would lead to the children feeling better about themselves when engaging in the activity, as it was a cool activity. Survey based evaluations of the VERB ${ }^{\mathrm{TM}}$ campaign (n $=2257$ to 3120) found it to be successful in its initial launch at increasing awareness [36] which was sustained up to 2 years after and indeed appeared to positively influence children's physical activity behaviours over this period [36, 38]. In these examples framing is being used as a promotional tool, a clear use of both social marketing and behavioural economics strategies in unison.

Another link back to the behaviour stage in the conceptual framework which was utilised by the VERB $^{\mathrm{TM}}$ campaign was the use of incentives. Prizes were used as incentives to those children partaking. Using incentives as a reward, or as a benefit of engaging in the desired behaviour was a 
common strategy and was also included in another study promoting healthier nutrition to children which was included in this review. The study aimed to understand what motivators could be used to make children choose the healthier food options at a restaurant, providing toys as an incentive was suggested as one possible method [29]. They concluded by suggesting that these methods could be implemented in future studies as they show promise in being effective in promoting healthier eating. Incentives were also used in a pilot study again wanting to increase the demand for the heathier meals in restaurants, and toys were given as an incentive to the children [38]. There was an increase in healthier meals being ordered reported from baseline to one month of the intervention, suggesting the potential for using these methods. Similarly, Hardman et al., [77] used incentives in their intervention aimed to increase girl's physical activity engagement, they used targets of daily pedometer step counts where if reached small rewards were given. This intervention reported that the experimental group, which included the small rewards, were significantly more active compared to the control both during the intervention and at follow up. It was concluded that the intervention was a promising strategy to increase physical activity in this population. Again, these examples demonstrate how the product (desired behaviour) is being promoted using incentives to children, which is an incorporation of both social marketing and behavioural economics strategies to ensure that the desired behaviour outweighs the undesired behaviour.

Linking back to the conceptual framework shown in figure 4, to achieve this aim of the first step there are 6 strategies that can be incorporated from both social marketing and behavioural economics: product, price, ego, priming, incentives and commitment. The product in this situation is the desired behaviour, either physical activity engagement or healthier nutrition, with the price being sacrificing sedentary time and unhealthier options - or vice versa. All studies included in the review met this as they were attempting to influence a child's health-related behaviour. There needs to be an emphasis on the feel-good factor associated with engaging in these positive health behaviours, this links to the ego aspect of behavioural economics. Numerous studies incorporated this into their study design [35, $36,45,47,48,53]$.

The behaviour can be framed in a way that presents it as a fun or enjoyable activity, rather than as a task or a necessity for health, this encompasses the research around framing from behavioural economics. Framing is an example of using priming, which was included in $88 \%$ of the studies included in the review. This relates to anytime consideration is given to either what information is given or how it is delivered, particularly when unconscious cues are used in an attempt to influence behaviour. 12 studies included in this review used priming [28, 34, 38, 74, 35, 36, 49, 48, 53, 70, 71, 72]. Furthermore, the benefits need to be emphasised, this can be done by providing incentives such as rewards as a benefit of engaging in the desired behaviour. Often with children they are given stickers, or reward charts, this also links back to the commitment strategy in behavioural economics. Once the children have started the chart, or colleting stickers, they will want to finish as people have a tendency to collect things [80]. Incentives were used in 13 of the studies included in this review [28, $29,34,36,37,38,47,48,53,70,75,76,77]$. Ensuring that all of these strategies are considered can help in promoting the desired behaviour over the un-desired behaviour.

Step 2: The Location - Consider carefully where the behaviour is engaged at and/or where you want to promote it

This step revolves around the need to consider where the behaviour is being engaged in and/or the importance of identifying a location to influence the behaviour. Point of decision prompts, or nudges, are one example of how this can be done and were used by a number of studies included in this review. One of these studies was conducted by Miller et al., [71]. This study investigated nudging in the pre ordering of school meals. A child would place their preferred lunch order in advance using an online system, this was the location chosen to promote the healthier behaviour. If after choosing their 
meal the child's choice was deemed unhealthy, they were given the message "your meal does not look like a balanced meal", advice on making this meal healthier, and offered a chance to amend their chosen items. If the child then preceded to amend their order to a healthier one, they were then shown an image of a smiley face and a statement saying that they have ordered a balanced meal; this being positive reinforcement. This is an example of how the researchers were nudging to make the children aware of their behaviours with the aim of promoting a healthier option. Indeed, students who pre-ordered and received nudges were more likely (51.4\%) to choose fruits, vegetables, and lowfat milk than those not receiving nudges.

Additionally, in the previous section a study using incentives to promote healthier food choice was discussed, this study also included elements of salience to increase the visibility of the desired behaviour, as well as nudges [29]. Servers prompted families with children to try the healthier menus, in addition to the signs that were used throughout the restaurant to promote the healthier options. Placemats were also used, so the promotion was placed right in front of the children. This strategy of increasing salience and nudging through the use of nudges placed in front of children was also incorporated by Sharps et al., [72] who found that using pictorial nudges on tableware influenced children's nutritional choices. This again is a demonstration of the incorporation of both social marketing and behavioural economics strategies. The place of the intervention was key to these studies, being where the nutritional choices were being made, this links to the place P of social marketing. Additionally, at these identified points behavioural economic strategies including nudging and priming were used to influence the behaviour. Here also an additional $\mathrm{P}$ of social marketing was used, promotion, through the use of promotional material.

Another popular method to increase the salience of the intended behaviour was through the incorporation of a brand. Brands are often used for identification and understanding of the product/behaviour/item being promoted [81]. Often the adoption of a pre-existing brand is particularly effective as it utilizes any pre-existing emotions a child has towards that brand [27], however creating new brands is also common. One study included in the review aimed to develop a branding strategy to improve the quality of food children brought into school, they hoped the brand would be an effective way to promote the desired behaviour [33]. Another study reported the influence that branding has over what, and how much children eat [55]. Indeed, the previously mentioned VERB ${ }^{\mathrm{TM}}$ campaign used a brand as an integral component of their intervention, as their aim was to become the children's brand for physical activity.

Branded food is also often promoted to children in movies through the use of product placements, and a study which used product placements to promote unhealthy foods to children was included in this review. Matthes and Naderer [60] investigated how exposure of a clip from a popular children film, with a product placement embedded, influenced the intake of the product being promoted after watching the clip. When films are used like this to promote a product, the products are often paired with the protagonist of the film, this associative pairing causes an affect transfer changing the attitude towards the product [45]. It was concluded that after being exposed to the branded food through the product placement in the film, there was a significant effect on consumption. Again, this provides evidence for the fact that these strategies are already being used together, and successfully, in interventions. This is an example of where the place of the promotion and inclusion of a brand, being social marketing strategies, is paired with the manipulation of the affective response to a film character to increase the products salience, being behavioural economics strategies, with the overall aim of influencing the behaviour.

The conceptual framework illustrates how four strategies from social marketing and behavioural economics can be used in this second step, when considering where the behaviour is being engaged in and/or the importance of identifying a location to influence the behaviour. Both social marketing 
and behavioural economics focus on specifically targeting the individual, therefore the location where the individual is going to engage in the behaviour or experience the strategies to influence their behaviour is key.

Priming and salience have an emphasis on the location, priming was incorporated in 12 of the included studies in the review $[28,43,38,74,35,36,47,48,53,70,71,72]$, and salience in was used in $84 \%$ of the included studies. Consideration needs to be given to where the strategies will be implemented, an aim of this is to make the target behaviour as convenient and pleasant as possible [23]. One way to achieve this is to use point of decision prompts, such as nudges at the specific location to prompt a particular behaviour, or to increase the visibility of the intended behaviour or promotional tool. The choice of location is important, this is illustrated by the fact that $94 \%$ of studies included in the review incorporated place as a strategy. Also, at the location there needs to be something that makes the message stand out and increase its salience, indeed this is a popular strategy as seem by the $84 \%$ of studies included in this review which incorporated salience strategies. The location itself, or the tools used at the location, can be made more appealing, and this can also links into the use of affect as by making it more appealing the aim is that positive emotions will be associated with these more appealing experiences. 22 studies included in this review incorporated the affect strategy [29, 30, 31, 32, 34, 35, 36, 37, 38, 41, 45, 47, 48, 49, 53, 58, 60, 64, 65, 66, 76, 78]. By using or considering all of these different strategies, careful consideration can be given to the location of the desired behaviour/intervention strategy to increase the chances if it being successful.

\section{Step 3: The Tools - Implement a range of different strategies to help promote the desired behaviour.}

The last step includes implementing a range of strategies to help promote the desired behaviour. One strategy is the use of norms. The previously mentioned VERB ${ }^{\mathrm{TM}}$ campaign can be used as an example of norms, as its aim was to influence the behavioural norms of children's physical activity. It also included characters, using characters as messengers was a popular technique incorporated by a number of studies included in this review, one being the VERB ${ }^{\mathrm{TM}}$ campaign. Figure 5 illustrates how the VERB ${ }^{\mathrm{TM}}$ campaign used characters to promote physical activity to children (using a full-page advertorial featuring the Marvel characters Wolverine and Nighcrawler) [82]. These characters are being used as the messengers to deliver the information to the children and as a promotional tool for physical activity engagement.

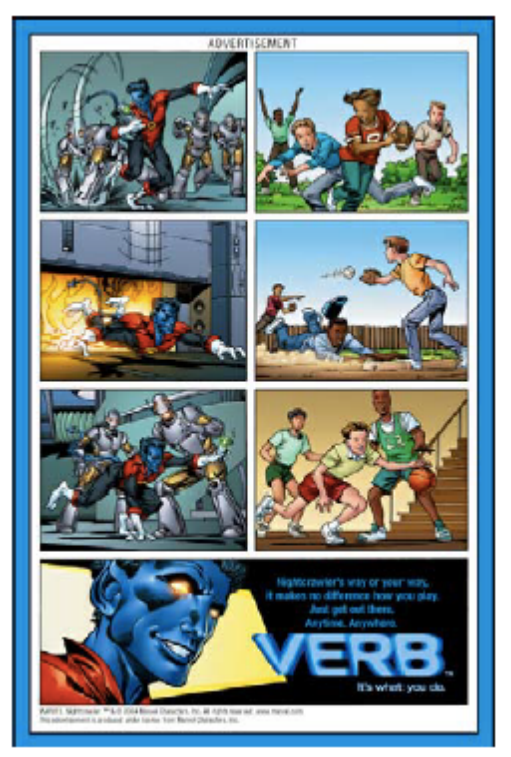

Figure 5: VERB advertorial with Marvel characters [82] 
As commented earlier, when characters are used and paired with a protagonist of the film, this associative pairing can cause an affect transfer to the product being advertised [45]. This strategy was used to successfully influence the food preferences of children in another study included in this review. Gunnarsdottir and Thorsdottir [64] investigated using popular branded characters on the wrapping of children's food to promote children's preferences for that food. They reported that this child orientated wrapping approach could be a popular way to promote healthy eating among children, this may be due to the fact that children often want to emulate popular characters that they are exposed to in the media [83]. Through using characters as a promotional tool, to deliver a message, and through the association with affect, both social marketing and behavioural economics strategies are being used together to influence the heath related behaviours of children.

Another tool included at this stage was defaults, interestingly defaults were not found in any of the included studies in this review. In a recent systematic review into specifically behavioural economic strategies on nutritional behaviours in children, it was also reported that few studies directly examined defaults alone but that those which did demonstrated high effectiveness [84] defaults are used children are prompted to stick to the "status quo" or to the "socially acceptable option", these can be influential in their decision making.

Linking back to the conceptual framework, this last step involves the implementation of the specific tools that will help to promote the desired behaviour. The promotion of a behaviour is one of the four Ps of social marketing and the included behavioural economics strategies in the conceptual framework are all tools that can be used in the promotion efforts. Using a messenger in the delivery is a key persuasion tool, especially when well-known characters are used to deliver a message to children. Messengers were used in 17 studies in this review [35, 36, 37, 45, 47, 48, 49, 50, 31, 53, 58, 60, $64,65,76,77,32]$. When popular media characters are incorporated then any pre-existing relationships and/or emotions towards that character are being played on, and thus this links to the importance of emotions and the affective response. Affect was included in 22 of the included studies $[29,30,31,32,34,35,36,37,38,41,45,47,48,49,53,58,60,64,65,66,76$, 78]. Behavioural economics posits that emotions influence behaviours, so if a positive emotion is experienced when engaging in a positive health behaviour, this may lead to increased engagement. Both positioning the behaviour as a norm so that the child perceives it as a behaviour that others commonly engage in, and presenting the desired behaviour as a default option, are also two additional tools that can be incorporated. These were two of the least common strategies, with norms being used in 5 studies [35, 36, 53, 47, 48] and no studies included in this review incorporated default options. By following this final step, considering and incorporating these many strategies, a multidisciplinary approach can be adopted in the pursuit of influencing children's health related behaviours.

\section{Future research and limitations}

This review has identified the combined presence of social marketing and behavioural economic strategies in a number of physical activity and nutritional interventions aimed at children. This has then been taken and presented in a conceptual framework to illustrate the clear links between the two strategies. This conceptual framework requires implementation and evaluation. However, it is suggested that by using this new framework, both social marketing and behavioural economics strategies may be able to be used holistically in future interventions. Future research should use this proposed framework as justification for the conceptual and practical alignment of the two research areas into one for the development, evaluation, and implementation of future interventions to increase their effectiveness.

Most interestingly this review has shown the influence that characters have over a child's engagement in a health-related behaviour, and that when incorporating characters numerous social 
marketing and behavioural economics strategies are being incorporated. Future studies should consider the use of this as an intervention for promoting positive health behaviours in children, for example promoting healthy nutrition or physical activity engagement, especially as the research into this in a physical activity setting is limited.

The final point to raise is again to highlight the large number of papers which found using these strategies can change behaviour, $95 \%$ of these papers with behaviour change outcomes reported the strategies employed led to behaviour change. Interestingly, one of the two papers which did not report a behaviour change only incorporated 5 of the strategies, this was below the average number of strategies incorporated. The other study which reported no behaviour change was actually a follow up 20 months post intervention. Although the study incorporated 7 of the strategies, the benefits initially seen were not sustained 20 months post intervention. However, the long-term implications of these interventions, and methods to sustain the impact of the strategies, which was not something considered in this review thus a limitation of the current study, should be something that future research investigates. One other limitation of this research which is worth noting is that a metaanalysis was not possible, due to the different outcome variables.

\subsection{CONCLUSION}

The findings from this review support the points raised by Dessart and van Bavel [20] in demonstrating the clear links, overlaps and consistency in the research around both behavioural economic strategies and social marketing, particularly in their attempted use to influence the physical activity and nutritional behaviours of children. In many cases the intervention was deemed to be a "social marketing intervention" however behavioural economics strategies were found to be incorporated. This suggests that despite the lack of acknowledgment, perhaps both strategies are often incorporated without intention. As such, the conceptual framework presented in this review is hoped to aid future interventions aiming to engage children in positive physical activity and nutritional behaviours as a way to include both social marketing and behavioural economics strategies. Future research should utilise the conceptual framework and use it in the development of future interventions

\subsection{REFERENCES}

1. World health Organisation. 2004 https://www.who.int/whr/2004/en/

2. European Commission, 2007. A Strategy for Europe on Nutrition, Overweight and Obesity related health issues. European Commission, Brussels

3. Kader, M., Sundblom, E., \& Elinder, L. S. (2015). Effectiveness of universal parental support interventions addressing children's dietary habits, physical activity and bodyweight: A systematic review. Preventive medicine, 77, 52-67.

4. Lipowska, M., \& Lipowski, M. (2018). Children's Awareness of Healthy Behaviours-Validity of Beauty \& Health and Dietary Knowledge \& Habits Scales. Health Psychol. Rep, 6.

5. Wilkie, H. J., Standage, M., Gillison, F. B., Cumming, S. P., \& Katzmarzyk, P. T. (2016). Multiple lifestyle behaviours and overweight and obesity among children aged 9-11 years: results from the UK site of the International Study of Childhood Obesity, Lifestyle and the Environment. BMJ open, 6(2), e010677

6. Dumuid, D., Olds, T., Lewis, L. K., Martin-Fernández, J. A., Barreira, T., Broyles, S., ... \& Kurpad, A. (2018). The adiposity of children is associated with their lifestyle behaviours: a cluster analysis of school-aged children from 12 nations. Pediatric obesity, 13(2), 111-119. 
7. Janssen, I., \& LeBlanc, A. G. (2010). Systematic review of the health benefits of physical activity and fitness in school-aged children and youth. International journal of behavioral nutrition and physical activity, 7(1), 1-16.

8. World Health Organization. 2018. https://www.who.int/news-room/fact-sheets/detail/physicalactivity

9. Sallis, J. F., Bull, F., Guthold, R., Heath, G. W., Inoue, S., Kelly, P., ... \& Lancet Physical Activity Series 2 Executive Committee. (2016). Progress in physical activity over the Olympic quadrennium. The Lancet, 388(10051), 1325-1336.

10. Ridgers, N. D., Timperio, A., Cerin, E., \& Salmon, J. O. (2014). Compensation of physical activity and sedentary time in primary school children. Medicine and science in sports and exercise, 46(8), 1564.

11. Farooq, M. A., Parkinson, K. N., Adamson, A. J., Pearce, M. S., Reilly, J. K., Hughes, A. R., ... \& Reilly, J. J. (2018). Timing of the decline in physical activity in childhood and adolescence: Gateshead Millennium Cohort Study. British journal of sports medicine, 52(15), 1002-1006.

12. Cooper, A. R., Goodman, A., Page, A. S., Sherar, L. B., Esliger, D. W., van Sluijs, E. M., ... \& Ekelund, U. (2015). Objectively measured physical activity and sedentary time in youth: the International children's accelerometry database (ICAD). International journal of behavioral nutrition and physical activity, 12(1), 1-10.

13. Jago, R., Baranowski, T., Watson, K., Bachman, C., Baranowski, J. C., Thompson, D., ... \& Moe, E. (2009). Development of new physical activity and sedentary behavior change self-efficacy questionnaires using item response modeling. International Journal of Behavioral Nutrition and Physical Activity, 6(1), 1-14.

14. Hills, A. P., Dengel, D. R., \& Lubans, D. R. (2015). Supporting public health priorities: recommendations for physical education and physical activity promotion in schools. Progress in cardiovascular diseases, 57(4), 368-374.

15. Garriguet, D. (2007). Les habitudes alimentaires des Canadiens. Rapports sur la santé, 18(2), 82-003.

16. Lorson, B. A., Melgar-Quinonez, H. R., \& Taylor, C. A. (2009). Correlates of fruit and vegetable intakes in US children. Journal of the American Dietetic Association, 109(3), 474-478.

17. Loewenstein, G., Asch, D. A., Friedman, J. Y., Melichar, L. A., \& Volpp, K. G. (2012). Can behavioural economics make us healthier?. Bmj, 344, e3482.

18. Hanoch, Y., Barnes, A., \& Rice, T. (Eds.). (2017). Behavioral economics and healthy behaviors: Key concepts and current research.

19. Mulderrig, J. (2017). Nudge and the politics of wellbeing: bringing biopower into dialogue with critical discourse analysis. Médiation et Information.

20. Dessart, F. J., \& van Bavel, R. (2017). Two converging paths: behavioural sciences and social marketing for better policies. Journal of Social Marketing.

21. French, J., \& Russell-Bennett, R. (2015). A hierarchical model of social marketing. Journal of Social Marketing.

22. Kotler, P., Roberto, E., \& Lee, N. (2002). Social marketing. Thousand Oaks, Calif: Sage.

23. Lee, N. R., \& Kotler, P. (2011). Social marketing: Influencing behaviors for good. Sage Publications.

24. Weinreich, N. K. (2006). What is social marketing. Weinreich Communications, 10.

25. Change4Life. 2019 https://www.nhs.uk/change4life/activities/train-like-a-jedi

26. Hong, Q. N., Fàbregues, S., Bartlett, G., Boardman, F., Cargo, M., Dagenais, P., ... \& Pluye, P. (2018). The Mixed Methods Appraisal Tool (MMAT) version 2018 for information professionals and researchers. Education for Information, 34(4), 285-291. 
27. Matjasko, J. L., Cawley, J. H., Baker-Goering, M. M., \& Yokum, D. V. (2016). Applying behavioral economics to public health policy: illustrative examples and promising directions. American journal of preventive medicine, 50(5), S13-S19.

28. Economos, C. D., Hyatt, R. R., Goldberg, J. P., Must, A., Naumova, E. N., Collins, J. J., \& Nelson, M. E. (2007). A community intervention reduces BMI z-score in children: Shape Up Somerville first year results. Obesity, 15(5), 1325-1336.

29. Anzman-Frasca, S., Folta, S. C., Glenn, M. E., Jones-Mueller, A., Lynskey, V. M., Patel, A. A., ... \& Lopez, N. V. (2017). Healthier children's meals in restaurants: an exploratory study to inform approaches that are acceptable across stakeholders. Journal of nutrition education and behavior, 49(4), 285-295.

30. Borzekowski, D. L., \& Robinson, T. N. (2001). The 30-second effect: an experiment revealing the impact of television commercials on food preferences of preschoolers. Journal of the American Dietetic Association, 101(1), 42-46.

31. de Droog, S. M., Buijzen, M., \& Valkenburg, P. M. (2014). Enhancing children's vegetable consumption using vegetable-promoting picture books. The impact of interactive shared reading and character-product congruence. Appetite, 73, 73-80.

32. Dovey, T. M., Taylor, L., Stow, R., Boyland, E. J., \& Halford, J. C. (2011). Responsiveness to healthy television (TV) food advertisements/commercials is only evident in children under the age of seven with low food neophobia. Appetite, 56(2), 440-446.

33. Folta, S. C., Koch-Weser, S., Tanskey, L. A., Economos, C. D., Must, A., Whitney, C., ... \& Goldberg, J. P. (2018). Branding a school-based campaign combining healthy eating and ecofriendliness. Journal of nutrition education and behavior, 50(2), 180-189.

34. Ho, S. S., Lwin, M. O., Sng, J. R., \& Yee, A. Z. (2017). Escaping through exergames: Presence, enjoyment, and mood experience in predicting children's attitude toward exergames. Computers in Human Behavior, 72, 381-389.

35. Huhman, M., Potter, L. D., Wong, F. L., Banspach, S. W., Duke, J. C., \& Heitzler, C. D. (2005). Effects of a mass media campaign to increase physical activity among children: year-1 results of the VERB campaign. Pediatrics, 116(2), e277-e284.

36. Huhman, M., Bauman, A., \& Bowles, H. R. (2008). Initial outcomes of the VERB ${ }^{\mathrm{TM}}$ campaign: tweens' awareness and understanding of campaign messages. American Journal of Preventive Medicine, 34(6), S241-S248.

37. Longacre, M. R., Roback, J., Langeloh, G., Drake, K., \& Dalton, M. A. (2015). An entertainmentbased approach to promote fruits and vegetables to young children. Journal of nutrition education and behavior, 47(5), 480-483.

38. Lopez, A., \& Rodriguez, R. (2018). Children and their brands: how young consumers relate to brands. Journal of Consumer Marketing.

39. Velazquez, C. E., \& Pasch, K. E. (2014). Attention to food and beverage advertisements as measured by eye-tracking technology and the food preferences and choices of youth. Journal of the Academy of Nutrition and Dietetics, 114(4), 578-582.

40. Williams, D. M. (2008). Exercise, affect, and adherence: an integrated model and a case for selfpaced exercise. Journal of Sport and Exercise Psychology, 30(5), 471-496.

41. Effertz, T., Teichert, T., \& Tsoy, M. (2019). Fast food, ads, and taste in a Russian child's mind. Psychology \& Marketing, 36(3), 175-187.

42. Chambers, T. I. M., Stanley, J., Pearson, A. L., Smith, M., Barr, M., Mhurchu, C. N., \& Signal, L. (2019). Quantifying children's non-supermarket exposure to alcohol marketing via product packaging using wearable cameras. Journal of Studies on Alcohol and Drugs, 80(2), 158-166. 
43. Emond, J. A., Longacre, M. R., Drake, K. M., Titus, L. J., Hendricks, K., MacKenzie, T., ... \& Dalton, M. A. (2019). Exposure to child-directed TV advertising and preschoolers' intake of advertised cereals. American journal of preventive medicine, 56(2), e35-e43.

44. Emond, J. A., Longacre, M. R., Drake, K. M., Titus, L. J., Hendricks, K., MacKenzie, T., ... \& Dalton, M. A. (2019). Influence of child-targeted fast food TV advertising exposure on fast food intake: A longitudinal study of preschool-age children. Appetite, 140, 134-141.

45. Beaufort, M. (2019). How candy placements in films influence children's selection behavior in real-life shopping scenarios-an Austrian experimental field study. Journal of Children and Media, 13(1), 53-72.

46. Andreyeva, T., Kelly, I. R., \& Harris, J. L. (2011). Exposure to food advertising on television: associations with children's fast food and soft drink consumption and obesity. Economics $\mathcal{E}$ Human Biology, 9(3), 221-233.

47. Berkowitz, J. M., Huhman, M., \& Nolin, M. J. (2008). Did augmenting the VERB ${ }^{\mathrm{TM}}$ campaign advertising in select communities have an effect on awareness, attitudes, and physical activity?. American Journal of Preventive Medicine, 34(6), S257-S266.

48. Huhman, M. E., Potter, L. D., Duke, J. C., Judkins, D. R., Heitzler, C. D., \& Wong, F. L. (2007). Evaluation of a national physical activity intervention for children: VERB ${ }^{\mathrm{TM}}$ campaign, 20022004. American journal of preventive medicine, 32(1), 38-43.

49. Bezbaruah, N., \& Brunt, A. (2012). The influence of cartoon character advertising on fruit and vegetable preferences of 9-to 11-year-old children. Journal of nutrition education and behavior, 44(5), 438-441.

50. Boyland, E. J., \& Halford, J. C. (2013). Television advertising and branding. Effects on eating behaviour and food preferences in children. Appetite, 62, 236-241.

51. Bruce, A. S., Lepping, R. J., Bruce, J. M., Cherry, J. B. C., Martin, L. E., Davis, A. M., ... \& Savage, C. R. (2013). Brain responses to food logos in obese and healthy weight children. The Journal of Pediatrics, 162(4), 759-764.

52. Buijzen, M., Rozendaal, E., \& de Droog, S. M. (2014). Food marketing and child health. Young People, Media and Health: Risks and Rights, 121-128.

53. Colquitt, G., Walker, A., \& Alfonso, M. (2014). Adapting a Community-Based Physical Activity Promotion Program for Rural, Diverse Youth. Physical Educator, 71(3), 514.

54. Dixon, H. G., Scully, M. L., Wakefield, M. A., White, V. M., \& Crawford, D. A. (2007). The effects of television advertisements for junk food versus nutritious food on children's food attitudes and preferences. Social science \& medicine, 65(7), 1311-1323.

55. Keller, K. L., Kuilema, L. G., Lee, N., Yoon, J., Mascaro, B., Combes, A. L., ... \& Halford, J. C. (2012). The impact of food branding on children's eating behavior and obesity. Physiology $\mathcal{E}$ behavior, 106(3), 379-386.

56. Harris, J. L., \& Kalnova, S. S. (2018). Food and beverage TV advertising to young children: Measuring exposure and potential impact. Appetite, 123, 49-55.

57. Haryanto, J. O., Moutinho, L., \& Coelho, A. (2016). Is brand loyalty really present in the children's market? A comparative study from Indonesia, Portugal, and Brazil. Journal of Business Research, 69(10), 4020-4032.

58. Hota, M., Cáceres, R. C., \& Cousin, A. (2010). Can Public-Service Advertising Change Children's Nutrition Habits?: The Impact of Relevance and Familiarity. Journal of Advertising Research, 50(4), 460-477.

59. Forman, J., Halford, J. C., Summe, H., MacDougall, M., \& Keller, K. L. (2009). Food branding influences ad libitum intake differently in children depending on weight status. Results of a pilot study. Appetite, 53(1), 76-83. 
60. Matthes, J., \& Naderer, B. (2015). Children's consumption behavior in response to food product placements in movies. Journal of Consumer Behaviour, 14(2), 127-136.

61. Norman, J., Kelly, B., McMahon, A. T., Boyland, E., Baur, L. A., Chapman, K., ... \& Bauman, A. (2018). Children's self-regulation of eating provides no defense against television and online food marketing. Appetite, 125, 438-444.

62. Norman, J., Kelly, B., McMahon, A. T., Boyland, E., Chapman, K., \& King, L. (2020). Remember Me? Exposure to Unfamiliar Food Brands in Television Advertising and Online Advergames Drives Children's Brand Recognition, Attitudes, and Desire to Eat Foods: A Secondary Analysis from a Crossover Experimental-Control Study with Randomization at the Group Level. Journal of the Academy of Nutrition and Dietetics, 120(1), 120-129.

63. Uribe, R., \& Fuentes-García, A. (2015). The effects of TV unhealthy food brand placement on children. Its separate and joint effect with advertising. Appetite, 91, 165-172.

64. Gunnarsdottir, I., \& Thorsdottir, I. (2010). Should we use popular brands to promote healthy eating among children?. Public health nutrition, 13(12), 2064-2067.

65. Letona, P., Chacon, V., Roberto, C., \& Barnoya, J. (2014). Effects of licensed characters on children's taste and snack preferences in Guatemala, a low/middle income country. International journal of obesity, 38(11), 1466-1469.

66. Kelly, B., Boyland, E., King, L., Bauman, A., Chapman, K., \& Hughes, C. (2019). Children's exposure to television food advertising contributes to strong brand attachments. International journal of environmental research and public health, 16(13), 2358.

67. Kent, M. P., Velazquez, C. E., Pauzé, E., Cheng-Boivin, O., \& Berfeld, N. (2019). Food and beverage marketing in primary and secondary schools in Canada. BMC public health, 19(1), 1-10.

68. Masterson, T. D., Bermudez, M. A., Austen, M., Lundquist, E., Pearce, A. L., Bruce, A. S., \& Keller, K. L. (2019). Food commercials do not affect energy intake in a laboratory meal but do alter brain responses to visual food cues in children. Appetite, 132, 154-165.

69. Smith, R., Kelly, B., Yeatman, H., Moore, C., Baur, L., King, L., ... \& Bauman, A. (2020). Advertising Placement in Digital Game Design Influences Children's Choices of Advertised Snacks: A Randomized Trial. Journal of the Academy of Nutrition and Dietetics, 120(3), 404-413.

70. Samek, A. (2019). Gifts and goals: Behavioral nudges to improve child food choice at school. Journal of Economic Behavior \& Organization, 164, 1-12.

71. Miller, G. F., Gupta, S., Kropp, J. D., Grogan, K. A., \& Mathews, A. (2016). The effects of preordering and behavioral nudges on National School Lunch Program participants' food item selection. Journal of economic psychology, 55, 4-16.

72. Sharps, M. A., Thomas, E., \& Blissett, J. M. (2020). Using pictorial nudges of fruit and vegetables on tableware to increase children's fruit and vegetable consumption. Appetite, 144, 104457.

73. Willi, S. M., Hirst, K., Jago, R., Buse, J., Kaufman, F., El Ghormli, L., ... \& HEALTHY Study Group. (2012). Cardiovascular risk factors in multi-ethnic middle school students: the HEALTHY primary prevention trial. Pediatric obesity, 7(3), 230-239.

74. Thomas, S. L., Olds, T., Pettigrew, S., Yeatman, H., Hyde, J., \& Dragovic, C. (2014). Parent and child interactions with two contrasting anti-obesity advertising campaigns: a qualitative analysis. BMC Public Health, 14(1), 1-11.

75. Gorely, T., Morris, J. G., Musson, H., Brown, S., Nevill, A., \& Nevill, M. E. (2011). Physical activity and body composition outcomes of the GreatFun2Run intervention at 20 month followup. International Journal of Behavioral Nutrition and Physical Activity, 8(1), 1-11.

76. Baranowski, T., Baranowski, J., Thompson, D., Buday, R., Jago, R., Griffith, M. J., ... \& Watson, K. B. (2011). Video game play, child diet, and physical activity behavior change: A randomized clinical trial. American journal of preventive medicine, 40(1), 33-38. 
77. Hardman, C. A., Horne, P. J., \& Lowe, C. F. (2009). A home-based intervention to increase physical activity in girls: the Fit 'n'Fun Dudes program. Journal of Exercise Science $\mathcal{E}$ Fitness, 7(1), 18.

78. Sauvage-Mar, C., Naylor, P. J., Higgins, J. W., \& VonBuchholz, H. (2019). Way2Go! Social marketing for girls' active transportation to school. Preventive medicine reports, 14, 100828.

79. Crawford (2019) Conceptual and theoretical frameworks in research, in Research design and methods. (pp35-47)

80. Larsson, R. S. (2013). Motivations in Sports and Fitness Gamification. Umea University.

81. Keller, K. L. (1998). Branding perspectives on social marketing. ACR North American Advances.

82. VERB advertorial (2005) https://www.google.com/url?sa=i\&url=https\%3A\%2F\%2Fstacks.cdc.gov\%2Fview\%2Fcdc\%2F4347 2\%2Fcdc_43472_DS1.pdf\%3F\&psig=AOvVaw2_UHncPbOKkSUfPR1IWv_\&ust=16125379408970 00\&source=images\&cd=vfe\&ved=0CAkQjhxqFwoTClizvIzC0O4CFQAAAAAdAAAAABAD

83. Moyer-Gusé, E. (2008). Toward a theory of entertainment persuasion: Explaining the persuasive effects of entertainment-education messages. Communication theory, 18(3), 407-425.

84. Chambers, T., Segal, A., \& Sassi, F. (2021). Interventions using behavioural insights to influence children's diet-related outcomes: A systematic review. Obesity Reviews, 22(2), e13152. 
Pre-Print 